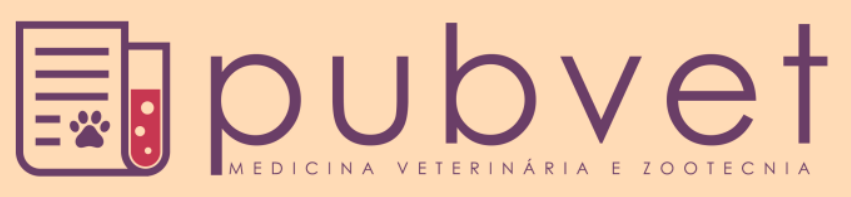

https://doi.org/10.22256/pubvet.v12n1a7.1-11

\title{
Avaliação da resposta inflamatória sistêmica induzida por carcinoma ductal in situ em cadelas
}

\author{
Paulo Henrique Braz ${ }^{\oplus} *$, Marcel Capelini Sartoretto ${ }^{\ominus}$, Gustavo Lourenço Lima ${ }^{\ominus}$, \\ Carolina Pereira Marinho ${ }^{\bullet}$, Marcos Eufrasio Bonato Xavier$^{2}$, Sandriele Goes de \\ Campos Deboleto ${ }^{\circ} 4$
}

${ }^{1}$ Docentes do Curso de Medicina Veterinária do Centro Universitário da Grande Dourados - UNIGRAN. Dourados - MS Brasil.E-mail: pauloh.braz@hotmail.com

${ }^{2}$ Discente do Curso de Medicina Veterinária do Centro Universitário da Grande Dourados - UNIGRAN. Dourados - MS Brasil.E-mail: m.c.marcel69@hotmail.com

${ }^{3}$ Médica Veterinária Aprimoranda em Clínica Médica e Cirúrgica de Pequenos Animais no Centro Universitário da Grande Dourados - UNIGRAN. Dourados - MS Brasil.E-mail: carolmarinho207@gmail.com

${ }^{4}$ Biomédica do Laboratório de Patologia Clínica no Centro Universitário da Grande Dourados - UNIGRAN. Dourados - MS Brasil. E-mail: sandrieledeboleto@outlook.com

*Autor para correspondência

RESUMO. Em tumores mamários, é comum alterações inflamatórias, causadas principalmente em neoplasias que metastatizam. Este trabalho tem por objetivo avaliar a concentração de Proteína C Reativa (PCR), correlacionada as alterações de proteínas totais e albumina em cadelas com carcinoma ductal in situ e demonstrar as alterações hematológicas encontradas. Foram utilizadas 13 cadelas diagnosticadas com carcinoma ductal in situ, triados pelo exame citopatológico e confirmado pela histopatologia. Concluise que a PCR é uma proteína de fase aguda que se eleva independente das proteínas totais e albumina e as alterações hematológica são de pouca relevância para o diagnóstico de carcinoma ductal in situ.

Palavras chave: proteínas de fase aguda, inflamação, tumor mamário canino, biomarcadores

\section{Evaluation of systemic inflammatory response induced by ductal carcinoma in situ in dogs}

ABSTRACT. In breast tumors, inflammatory changes are common, mainly caused by
neoplasias that metastasize. This work aims to evaluate the concentration of C Reactive
Protein (CRP), correlating the alterations of total proteins and albumin in dogs with ductal
carcinoma in situ and to demonstrate the hematological alterations found. Thirteen dogs
diagnosed with ductal carcinoma in situ were screened by cytopathological examination
and confirmed by histopathology. It is concluded that CRP is an acute phase protein that
rises independently of total proteins and albumin and hematological changes are of little
relevance for the diagnosis of ductal carcinoma in situ.

Keywords: acute phase proteins, inflammation, canine mammary tumor, biomarkers

\section{Evaluación de la respuesta inflamatoria sistémica inducida por carcinoma ductal in situ en perras}

RESUMEN. En tumores mamarios, es común alteraciones inflamatorias, causadas principalmente en neoplasias que hacen metástasis. Este trabajo tiene por objetivo evaluar 
la concentración de Proteína C Reactiva (PCR), correlacionada con las alteraciones de proteínas totales y albúmina en perras con carcinoma ductal in situ y demostrar los cambios hematológicos encontrados. Se utilizaron 13 perras diagnosticadas con carcinoma ductal in situ, clasificadas por el examen citopatológico y confirmado por la histopatología. Se concluye que la PCR es una proteína de fase aguda que se eleva independientemente de las proteínas totales y albúmina y los cambios hematológicos son de poca relevancia para el diagnóstico de carcinoma ductal in situ.

Palabras clave: proteínas de fase aguda, inflamación, tumor mamario canino, biomarcadores

\section{Introdução}

O organismo possui alguns mecanismos de defesa contra agentes agressores, a primeira reação a um destes agentes é a resposta inata, não específica. A resposta de fase aguda trata-se de uma reação sistêmica que se desenvolve após o organismo ser exposto a algum distúrbio local ou sistêmico, que podem ser ocasionados por agentes infecciosos, lesões tissulares, traumas ou procedimentos cirúrgicos, neoplasias ou processos inflamatórios (Gruys et al., 2005, Carvalho et al., 2008).

Em processos inflamatórios ocorre a liberação por parte do organismo de proteínas de fase aguda (APPs), dentre as proteínas que aumentam na inflamação, chamadas de APPs positivas. A Proteína C-Reativa (PCR) é uma das mais importantes, pois tem uma função semelhante à de um anticorpo, devido ao fato de realizar a ativação do sistema complemento, fazendo com que fagócitos captem patógenos. Além disso, a PCR pode neutralizar a produção de superóxido, realizar degranulação neutrofílica e minimizar o acúmulo de neutrófilos em tecidos inflamados (Gershov et al., 2000, Squassoni et al., 2011).

Realizar a quantificação das APPs é um método importante de verificar a resposta inata do sistema imunológico do organismo frente a agentes agressores ou alterações do próprio organismo. As APPS são classificadas como positivas quando estão aumentadas ou negativas quando estão diminuídas. As concentrações destas proteínas podem ter o seu valor aumentado ou diminuído em $25 \%$ em relação a valores normais, dependendo do distúrbio a que o organismo está sendo acometido (Jain et al., 2011).

Várias doenças em caninos acarretam aumento nos níveis séricos de PCR como, por exemplo, leptospirose, parvovirose, babesiose, também ocorre em tumores (linfoma e hemangiossarcoma) e traumas cirúrgicos, além de pancreatite aguda, anemia imunomediada, artrite, glomerulonefrite e processos inflamatórios experimentais (Nakamura et al., 2008, Anziliero et al., 2013).

A prevalência dos tumores mamários faz com que diferentes técnicas laboratoriais sejam estudadas para auxiliar no prognóstico e tratamento do paciente com câncer mamário.

\section{Material e Métodos}

O experimento teve aprovação do Comitê de Ética para Uso Animal (CEUA-UNIGRAN) com protocolo 011/15 e executado no Laboratório de Patologia Clínica Veterinária, situado no Hospital Veterinário da UNIGRAN, localizado no município de Dourados-MS. As amostras de sangue foram colhidas entre os meses de novembro de 2015 a abril de 2016 para a obtenção de soro e execução dos exames de Proteína-CReativa, albumina, proteínas totais e hemograma.

Foram utilizadas 13 cadelas diagnosticadas com neoplasia mamária, do tipo carcinoma ductal in situ, triados pelo exame citopatológico e confirmado pela histopatologia. Após confirmado o diagnóstico, realizou-se à colheita de sangue venoso e o sangue acondicionados em dois tubos, sendo um com anticoagulante do tipo EDTA-K2 para realização da análise hematológica, e outro tubo sem anticoagulante para exames bioquímicos séricos de albumina e proteínas totais.

Para realização dos exames de PCR foi utilizado $25 \mu \mathrm{l}$ de amostra de soro, usando-se partículas de látex revestidas com anticorpo monoclonal anti-PCR por aglutinação indireta, para instilação no Kit comercial (Wama Diagnóstica $^{\circledR}$ ), considerado negativo quando havia total ausência de aglutinação, indicativo de concentração inferior a $6 \mathrm{mg} / \mathrm{litro}$. Quando ocorreu aglutinação do soro, a concentração era igual ou superior a $6 \mathrm{mg} / \mathrm{litro}$. As amostras positivas eram diluídas em salina $(\mathrm{NaCl}$ a $0,9 \%)$ nas proporções 1:2, 1:4, 1:8, 1:16 para semiquantificar o resultado. Os resultados do PCR dos cães foram comparados aos testes bioquímicos de 
albumina, proteínas totais e do hemograma utilizando-se o teste de Exato de Fischer.

\section{Resultado e discussão}

Dentre os animais examinados, a PCR foi positiva em $23,1 \%(n=3)$. Quando correlacionado as alterações séricas de proteínas totais e albumina com os valores semi-quantitativos de PCR aumentados $(\mathrm{P}<0,05)$ foi possível notar que não houve relação de dependência entre os testes; isso ocorre devido a PCR ser uma proteína de fase aguda elevando-se independentemente das proteínas analisadas.

A hiperproteinemia ocorreu devido às complicações paraneoplásicas em 23,1\% (n=3) dos animais estudados, como relatado por Dobson et al. (2006), em pacientes com mieloma ou leucemia crônica. Calazans et al. (2009) notaram que o valor de proteínas totais em cães sadios é menor do que em cães com linfoma.

Foi observado que a principal alteração nos níveis séricos de albumina foi a hipoalbuminemia, ocorrendo em 46,1\% $(n=6)$ dos animais estudados. De acordo com Murata et al. (2004), a hipoalbuminemia em mamíferos portadores de neoplasias ocorre devido à albumina ser uma proteína de fase aguda negativa, por isso quando há presença de inflamação aguda, a concentração sérica diminui.

A necessidade de correlação entre o desenvolvimento do câncer e inflamação ocorre, devido a resposta inflamatória de defesa como moderadora para a reparação e regeneração tecidual. Isso pode ocorrer devido aos danos teciduais de forma infecciosa ou não infecciosa (Balkwill and Mantovani, 2001, Coussens and Werb, 2002, Braz et al., 2016). Braz et al. (2016) demonstraram que presença de infiltrado inflamatório em neoplasias, dificultando o diagnóstico, podendo as células neoplásicas serem confundidas com células displásicas, causadas pela inflamação.

Foi possível notar que os carcinomas mamários ductal in situ geram uma inflamação do tipo leve, sendo que em todos os casos a concentração de PCR foi de $6 \mathrm{mg} / \mathrm{dL}$. A PCR geralmente se eleva em processos inflamatórios leves com aumento entre de 10-40 mg/L. Já em inflamações mais severas e infecções bacterianas, as concentrações séricas elevam-se entre 40-200 mg/L (Aguiara et al., 2013).

Tabela 1. Valores Hematológicos dos 13 animais com carcinomas mamários ductal in situ, diagnosticados entre o período de novembro de 2015 a abril de 2016

\begin{tabular}{|c|c|c|c|}
\hline Indice & Média & Desvio Padrão & Valores de Referência \\
\hline Leucócitos $\left(\mathrm{x} 10^{3} / \mu \mathrm{L}\right)$ & 12607,69 & 5868,096 & $6.000-17.000$ \\
\hline Hemácias (milhões/mm3) & 5,28 & 0,75 & $5,5-8,0$ \\
\hline Hemoglobina (g/dL) & 11,12 & 1,9 & $10,0-18,0$ \\
\hline Hematócrito (\%) & 35,9 & 8,02 & $35-55$ \\
\hline Neutrófilos (células/ $\mu$ l) & 9379,554 & 4901,22 & $3.000-11.5000$ \\
\hline Linfócitos (células/ $\mu$ l) & 1472,954 & 820,7222 & $1.000-4.800$ \\
\hline Eosinófilos (células/ $\mu 1$ ) & 804,2923 & 1184,562 & $150-1.250$ \\
\hline Plaquetas $(/ \mathrm{mm})$ & 184.077 & 89800,17 & $180.000-400.000$ \\
\hline
\end{tabular}

Todos os parâmetros hematológicos dos cães examinados permaneceram dentro dos valores de referência. Resultados diferentes foram observados por Silva et al. (2014) que encontraram alterações em $24,2 \%$ dos pacientes (39/161), sendo 18 animais com alterações no eritrograma e 30 no leucograma.

Em animais com neoplasias é comum à ocorrência de alterações hematológicas como anemia e trombocitopenia, porém existem poucos relatos, sobre a incidência, prevalência e sua importância clínica, apesar de ser descrita na literatura veterinária (Childress, 2012). Para Coussens and Werb (2002) as agressões aos tecidos causadas pelos tumores, provocam uma resposta inflamatória a fim de sanar as lesões desencadeadas, para isso ocorre à liberação de leucócitos como neutrófilos, monócitos, e eosinófilos na corrente sanguínea, para que alcancem o local acometido. Devido à produção de citocinas e quimiocitocinas pelas células tumorais, vários leucócitos são atraídos ao local da lesão, como neutrófilos, células dendríticas, macrófafos, eosinófilos, mastócitos e linfócitos. Nas neoplasias são encontradas células 
inflamatórias e plaquetas ativadas (Mueller and Fusenig, 2004, Desmoulière, 2008).

\section{Conclusões}

A PCR pode ser utilizada para acompanhar o quadro clínico do paciente, com diagnóstico de inflamações agudas precocemente, visto que as neoplasias desencadeiam um processo inflamatório. A hiperproteinemia e a hipoalbuminemia foram achados importantes para correlacionar com a alteração da PCR.

Os valores hematológicos não demonstraram boa sensibilidade para o acompanhamento do quadro clínico do animal com carcinoma ductal in situ, quando analisado isoladamente. No entanto, em quadros crônicos é possível que haja alterações, com aumento de neutrófilos em bastões, embora não tenha sido encontrado neste estudo.

\section{Referências Bibliográficas}

Aguiara, F. J. B., Ferreira-Júnior, M., Sales, M. M., Cruz-Neto, L. M., Fonseca, L. A. M., Sumita, N. M., Duarte, N. J. C., Lichtenstein, A. \& Duarte, A. J. S. 2013. Proteína C reativa: aplicações clínicas e propostas para utilização racional. Revista da Associação Médica Brasileira, 59, 85-92.

Anziliero, D., Bassi, E., Pain, K. M., Faria Valle, S. \& Kreutz, L. C. 2013. Determinação dos níveis séricos de proteína C-reativa (CRP) em cães com alterações dos parâmetros hematológicos. Ciência Animal Brasileira, 14, 265-272.

Balkwill, F. \& Mantovani, A. 2001. Inflammation and cancer: back to Virchow? The Lancet, 357, 539-545.

Braz, P. H., Brum, K. B., Souza, A. I. \& Abdo, M. A. G. S. 2016. Comparação entre a citopatologia por biopsia com agulha fina e a histopatologia no diagnóstico das neoplasias cutâneas e subcutâneas de cães. Pesquisa Veterinária Brasileira, 36, 197-203.

Calazans, S. G., Daleck, C. R., Fagliari, J. J., Repetti, C. F., De Nardi, A. B., Castro, J. H. T., Fernandes, S. C., César, J. R. F. \& Rodigheri, S. M. 2009. Proteinograma sérico de cães sadios e com linfoma obtido por eletroforese em gel de poliacrilamida (SDS-PAGE). Arquivo Brasileiro de Medicina Veterinária e Zootecnia, 61, 1044-1048.
Carvalho, C. C. D., Rêgo, E. W., Queque, M. \& Soares, P. C. 2008. Avaliação da proteína C reativa, fibrinogenio e leucograma em cadelas com piometra. Medicina Veterinária, 2, 3-10.

Childress, M. O. 2012. Hematologic abnormalities in the small animal cancer patient. Veterinary Clinics of North America-Small Animal Practice, 42, 123-155.

Coussens, L. M. \& Werb, Z. 2002. Inflammation and câncer. Nature, 420, 19-26.

Desmoulière, A. 2008. Tumors: wounds that do not heal. Similarities between tumor stroma generation and wound healing. New England Journal of Medicine, 315, 1650-1659.

Dobson, J., Villiers, E. \& Morris, J. 2006. Diagnosis and management of leukaemia in dogs and cats. In practice, 28, 22-31.

Gershov, D., Kim, S., Brot, N. \& Elkon, K. B. 2000. C-reactive protein binds to apoptotic cells, protects the cells from assembly of the terminal complement components, and sustains an antiinflammatory innate immune response. Journal of Experimental Medicine, 192, 1353-1364.

Gruys, E., Toussaint, M. J. M., Niewold, T. A. \& Koopmans, S. J. 2005. Acute phase reaction and acute phase proteins. Journal of Zhejiang University Science, 6, 1045-1056.

Jain, S., Gautam, V. \& Naseem, S. 2011. Acutephase proteins: As diagnostic tool. Journal of Pharmacy and Bioallied Sciences, 3, 118-127.

Mueller, M. M. \& Fusenig, N. E. 2004. Friends or foes-bipolar effects of the tumour stroma in cancer. Nature Reviews Cancer, 4, 839-849.

Murata, H., Shimada, N. \& Yoshioka, M. 2004. Current research on acute phase proteins in veterinary diagnosis: an overview. The Veterinary Journal, 168, 28-40.

Nakamura, M., Takahashi, M., Ohno, K., Koshino, A., Nakashima, K., Setoguchi, A., FUJINO, Y. \& Tsujimoto, H. 2008. C-reactive protein concentration in dogs with various diseases. Journal of Veterinary Medical Science, 70, 127-131.

Silva, A. H. C., Silva, D. M., Ribas, C. R., Dittrich, R. L., Dornbusch, P. T. \& Guérios, S. D. 2014. Alterações no hemograma de cadelas com neoplasia mamária. Ciência Animal Brasileira, $15,87-92$. 
Squassoni, G. F., Motheo, T. F., Feliciano, M. A. R. \& Vicente, W. R. R. 2011. Concentração sérica de proteína c-reativa em cadelas hígidas, gestantes ou com piometra. Revista Científica Eletrônica de Medicina Veterinária, 9, 1-8.
Article History:

Received 4 August 2017

Accepted 5 September 2017

Available on line 10 October 2017

License information: This is an open-access article distributed under the terms

of the Creative Commons Attribution License 4.0, which permits unrestricted

use, distribution, and reproduction in any medium, provided the original work is properly cited 